University of St. Thomas, Minnesota

UST Research Online

$2-21-2011$

\title{
Prevalence of children with disabilities in the child welfare system and out of home placement: An examination of administrative records
}

\author{
Katharine M. Hill \\ University of St.Thomas, Minnesota, kmhill1@stthomas.edu \\ Traci LaLiberte \\ Elizabeth Lightfoot
}

Follow this and additional works at: https://ir.stthomas.edu/ssw_pub

Part of the Clinical and Medical Social Work Commons, and the Social Work Commons

This Article is brought to you for free and open access by the School of Social Work at UST Research Online. It has been accepted for inclusion in Social Work Faculty/Staff Publications by an authorized administrator of UST Research Online. For more information, please contact asle4660@stthomas.edu. 
Provided for non-commercial research and education use. Not for reproduction, distribution or commercial use.

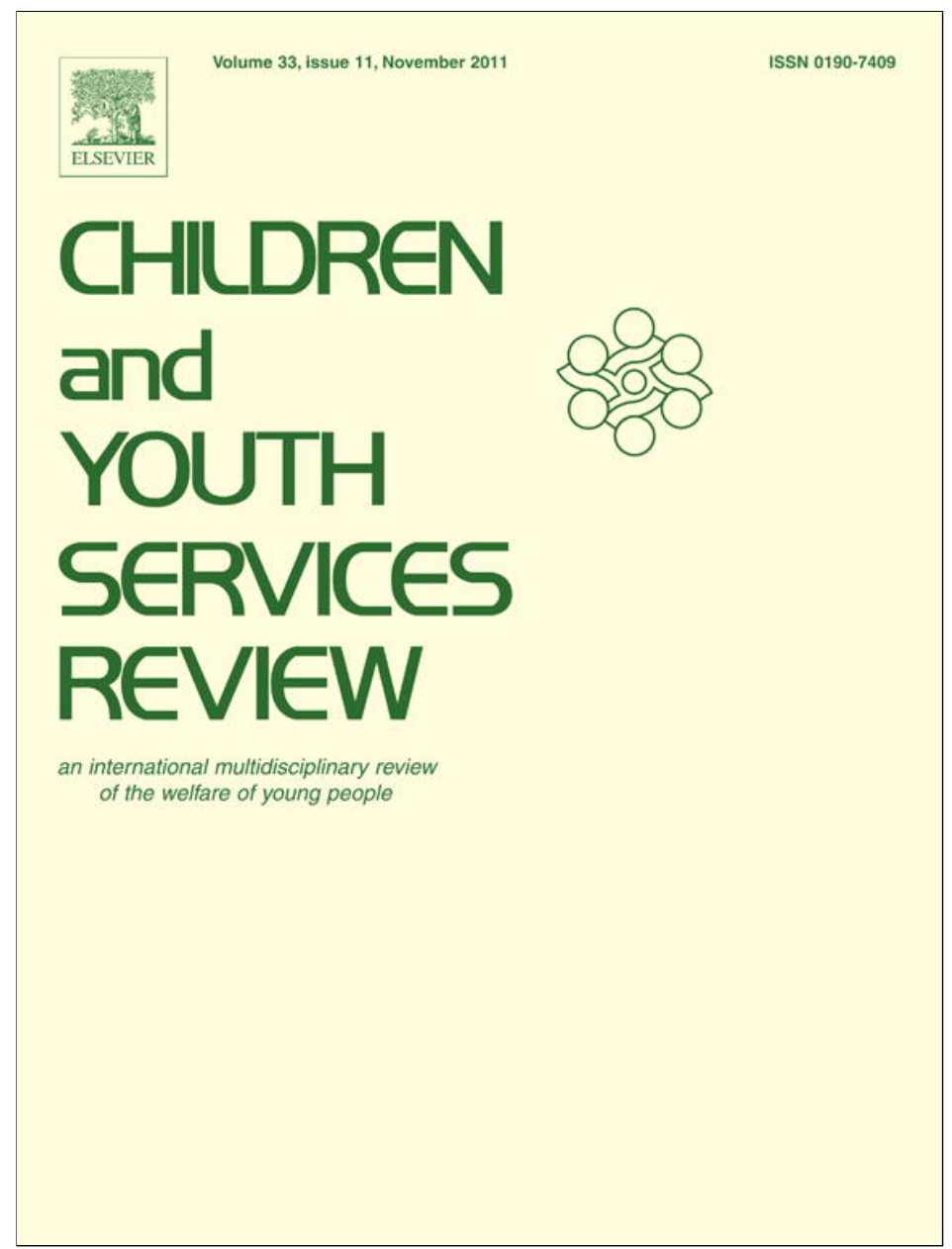

This article appeared in a journal published by Elsevier. The attached copy is furnished to the author for internal non-commercial research and education use, including for instruction at the authors institution and sharing with colleagues.

Other uses, including reproduction and distribution, or selling or licensing copies, or posting to personal, institutional or third party websites are prohibited.

In most cases authors are permitted to post their version of the article (e.g. in Word or Tex form) to their personal website or institutional repository. Authors requiring further information regarding Elsevier's archiving and manuscript policies are encouraged to visit:

http://www.elsevier.com/copyright 


\title{
Prevalence of children with disabilities in the child welfare system and out of home placement: An examination of administrative records
}

\author{
Elizabeth Lightfoot ${ }^{\mathrm{a}, *}$, Katharine Hill ${ }^{\mathrm{b}}$, Traci LaLiberte ${ }^{\mathrm{c}}$ \\ a School of Social Work, University of Minnesota, 105 Peters Hall, 1404 Gortner Avenue, St. Paul, MN 55108, United States \\ b School of Social Work, University of St. Thomas, St. Paul, MN 55104, United States \\ ' Center for the Advanced Studies of Child Welfare, School of Social Work, University of Minnesota, 105 Peters Hall, 1404 Gortner Avenue, St. Paul, MN 55108, United States
}

\section{A R T I C L E I N F O}

\section{Article history:}

Received 1 December 2010

Received in revised form 14 February 2011

Accepted 15 February 2011

Available online 21 February 2011

\section{Keywords:}

Child welfare

Children with disabilities

Out of home placement

Child maltreatment

Foster care

Child protection

\begin{abstract}
A B S T R A C T
This article explores the prevalence and characteristics of children with disabilities within the child welfare system using administrative data from the State of Minnesota. This study finds that more than a fifth (22\%) of children with substantiated maltreatment are labeled in administrative records as having a disability, and more than one quarter of children (27.9\%) over age five. The most common type of disability among children with substantiated maltreatment was emotional disturbance, while other common disabilities included intellectual and developmental disabilities and learning disabilities. Using logistic regression, this study finds that children with substantiated maltreatment with disabilities were about two times more likely to be in out of home placement than children with substantiated maltreatment without disabilities.
\end{abstract}

(c) 2011 Elsevier Ltd. All rights reserved.

\section{Introduction}

Over the past twenty years, studies have found that children and youth with disabilities experience a higher rate of maltreatment than children and youth without disabilities (American Academy of Pediatrics, 2001; Crosse et al., 1992; Sullivan \& Knutson, 1998, 2000; Verdugo \& Bermejo, 1995; Westcott \& Jones, 1999). While there has been much exploration into the factors related to these high rates of maltreatment (AAP, 2001; Westcott \& Jones, 1999), there is little known about how children with disabilities are served within the child welfare system (Lightfoot \& LaLiberte, 2006). There is limited data on the prevalence, the characteristics, or the out-of-home placement status of children with disabilities who are actively involved in the child welfare system. Without a clear sense of the prevalence of children with disabilities in the child welfare system and the characteristics of these children, it is exceedingly difficult to provide appropriate services and supports for children and their families (Bruhn, 2003; Horner-Johnson \& Drum, 2006). The purpose of this study is to explore the prevalence and characteristics of children with disabilities within the child welfare system in Minnesota using administrative data, and to compare the characteristics of children with disabilities with those of children without

\footnotetext{
* Corresponding author. Tel.: +1 612624 4710; fax: +1 6126243744.

E-mail addresses: elightfo@umn.edu (E. Lightfoot), Kmhill1@stthomas.edu (K. Hill), Lali@umn.edu (T. LaLiberte).
}

disabilities, focusing particularly on ethnicity, gender, rural/urban location, and out-of-home placement rates.

\section{Literature review}

The majority of research conducted on child maltreatment and children with disabilities has been conducted in the United States, with a few studies conducted in Canada, Western Europe and Australia. Although research is limited, studies have indicated that the maltreatment rate of youth with disabilities is higher than among their peers without disabilities. Crosse et al. (1992) found that the prevalence of maltreatment among children with disabilities was 1.7 times higher than the prevalence of maltreatment for children without disabilities, while Sullivan and Knutson (2000) found that children with disabilities were 3.4 times more likely to be maltreated than their peers without disabilities. Studies have had varied results in identifying the impact of a child with disability's gender, race or ethnicity, or geographic location on the likelihood of their suffering maltreatment. Most of the existing research has not focused on the causes of abuse, nor on the likelihood or efficacy of various interventions. This study uses state administrative data to examine the prevalence of youth with disabilities in the child welfare system in Minnesota, as well as the correlation between demographic characteristics (i.e. race, gender, and geographic location) and the likelihood that a young person is identified as having a disability. Finally, it examines the correlation between a child having a disability 
diagnosis in the child welfare system and their likelihood of being placed in out of home placement.

\subsection{Prevalence studies}

Westcott and Jones (1999) reviewed research conducted on the prevalence of abuse of children with disabilities between 1968 and 1999. The majority of the included studies examined existing records, such as case or medical records to determine the prevalence of maltreatment among children with disabilities. Early studies also tended to focus on disability and impairment among children who were maltreated, rather than on abuse or maltreatment of children with disabilities. Findings from these studies varied widely, with prevalence of disability among maltreated children ranging from $22 \%$ to $70 \%$ of those sampled (Sobsey, 1994). The few studies that focused on identifying the rate of maltreatment for children with disabilities found that the rates of abuse were higher for this population, although findings varied widely, depending on sample, setting, and methodologies (Sobsey, 1994; Westcott \& Jones, 1999).

In more recently completed studies, the focus has moved away from treating the abuse of children with disabilities as a "medical curiosity" to emphasizing their right to protection and safety (Westcott \& Jones, 1999). One of the key studies on prevalence of maltreatment among children with disabilities was completed by Westat in 1992, working with the National Center on Child Abuse and Neglect (NCCAN), to comply with the requirements of Child Abuse Prevention, Adoption, and Family Services Act of 1988. Data were collected from 35 child protection agencies statistically selected by researchers to be nationally representative. Each agency was asked to provide information on all cases of substantiated maltreatment over a 4-6 week time period in 1991; researchers conducted follow up interviews with caseworkers in 1991. In total, they sampled 1600 children without disabilities and 234 children with disabilities (Crosse et al., 1992).This study improved on much of the previous research by collecting data from a large number of cases in a national sample, having comparison groups of children with and without disabilities, having a stated definition of both abuse and disability and including an analysis of the abuse-impairment relationship (Westcott \& Jones, 1999). This study found that the prevalence of maltreatment among children with disabilities was 1.7 times higher than the prevalence of maltreatment for children without disabilities. It has been suggested that the Westat findings may underestimate the prevalence of children with disabilities in the sample population, because the researchers limited their sample to intra-familial abuse, therefore missing cases where the child was maltreated by a non-family caregiver (AAP, 2001). In addition, as caseworkers were responsible for identifying disability, they likely were less able to identify all children with disabilities (Lightfoot \& LaLiberte, 2006).

Sullivan and Knutson $(1998,2000)$ studies of child maltreatment prevalence use an epidemiological approach, merging child maltreatment records with other records in the Omaha, Nebraska region. The first study involved an electronic merger of databases comprising hospital, central registry, foster care, and law enforcement records to identify child abuse among patients at a hospital in Nebraska (Sullivan \& Knutson, 1998); and the second was for the entire school-based population of over 50,000 children enrolled in Public and Archdiocese schools in Omaha (Sullivan and Knutson, 2000). The rate of maltreatment among children with an identified disability for which they were receiving special education services was $31 \%$, thus children with disabilities were 3.4 times more likely to be maltreated than their peers without disabilities.

Verdugo and Bermejo (1995) studied children with intellectual disabilities in institutions in Castilla-Leon, Spain, using surveys of professionals who worked with families with children with intellectual disabilities, combined with case record review of cases involved in the child protection system. This study found that $11.5 \%$ of the children with disabilities had experienced some type of maltreatment, in comparison to $1.5 \%$ of the children without disabilities in the control group. Jonson-Reid, Drake, Kim, Porterfield, and Han (2004) conducted a prospective analysis of the relationship between reported child maltreatment and special education eligibility for children whose families received AFDC between 1993 and 1994. The authors combined state and local administrative databases to establish cross-sector service histories. These databases included child Medicaid health records, adult Medicaid mental health/ substance abuse services during childhood, AFDC records, child abuse and neglect reporting records, child welfare services information, and special education records. The researchers found that $24 \%$ of the children with substantiated maltreatment reports entered special education, compared with $14 \%$ of the children without maltreatment reports.

Along with general prevalence studies of child maltreatment of children with disabilities, there have been a number of studies examining how likely children in out of home placement through the child welfare system were likely to be in special education services. In a meta-analysis of thirty-one studies, Scherr (2007) found that children in out-of-home foster care is disproportionately represented in special education. For example, Goerge et al. (1992) found that 30\% of the school-age foster care population was identified as receiving special education services, and Smithgall, Gladden, Yang, and Goerge (2005) found that students in out-of-home care had a higher prevalence of disability, specifically emotional disturbance, as compared to the school age population.

One of the only studies to examine out of home placement of children with disabilities focused on young children aged birth-three using AFSCAR data (Rosenberg \& Robinson, 2004). This study found that young children with developmental or health conditions were more likely to be placed out of the home, experience longer stays in foster care, and have a deceased likelihood of returning to their parental home.

\subsection{Demographics, types of maltreatment, and disability}

From the studies of child maltreatment and children with disabilities, there is a growing knowledge base regarding the types of maltreatment that children with disabilities experience, the differences in prevalence and types of maltreatment a child might experience depending on the type of his or her disability, and the relationship among demographics, child maltreatment and disability.

Prevalence studies as well as reports that are more anecdotal point to neglect as the most common type of maltreatment experience by children with disabilities. For example, Crosse et al. (1992) found that the prevalence of emotional neglect among maltreated children with disabilities was 2.8 times greater than for maltreated children without disabilities. Likewise, Sullivan and Knutson (2000) found that children with disabilities were 3.76 times more likely to be victims of neglect than children without disabilities. Children with disabilities were more likely to have been medically neglected but less likely to be physically neglected than were children without disabilities (Crosse et al., 1992). However, while neglect is the most prevalent form of maltreatment, children with disabilities experience all forms of maltreatment at a greater rate than those without disabilities. Crosse et al. (1992) found the rate of physical abuse was 2.1 times greater, sexual abuse 1.8 times higher, and physical neglect 1.6 times higher for children with disabilities; while Sullivan and Knutson (2000) found that children with disabilities were 3.79 times more likely to be physically abused, 3.14 times more likely to be sexually abused, and 3.88 times more likely to be emotionally abused. Children with disabilities are also more likely to experience multiple types of maltreatment than children without disabilities (Sullivan \& Knutson, 2000; Verdugo \& Bermejo, 1995). 
Maltreatment rates have also been found to vary based on type of disability. Sullivan and Knutson (2000) found that the maltreatment of children with an "educationally relevant" disability (excluding autism), such as behavior disorders, communication disorders, health or orthopedic disabilities, or mental retardation, exceeded the maltreatment rate of children without an educationally relevant disability (Sullivan \& Knutson, 2000). Crosse et al. (1992) found that children with serious emotional disturbances and physical health problems were more likely to have reported maltreatment. Children in this study had lower reported rates of learning disabilities and similar rates of speech or language delay/impairment and of mental retardation than children in the general population (Crosse et al., 1992). Verdugo and Bermejo (1995) also found that children with behavior disorders were more likely to experience maltreatment. In addition, they found that, in general, the less a child had a functional impairment, the more likely he or she would experience maltreatment. However, for children with communication difficulties, the more serious their communication impairment, the more likely they were to be maltreated.

Research has been mixed regarding the types of maltreatment that children with disabilities experience based on type of disability. For example, Sullivan and Knutson (2000) did not find a significant association between a child's type of disability and the type of maltreatment endured. Conversely, Crosse et al. (1992) found that children with emotional disturbance, learning disability, and speech or language delay or impairment were most likely to have a substantiated maltreatment report with child protection services. Jonson-Reid et al. (2004) found that more than $21 \%$ of children with first reports of physical abuse had a diagnosis of serious emotional disturbance. Children with a diagnosis of mental retardation were more likely to enter the child welfare system with a report of neglect, and cases involving sexual abuse had the highest rate of diagnosis for learning disabilities. Children with early childhood delays or health impairments were most likely to suffer mixed-type maltreatment (Jonson-Reid et al., 2004).

Research has been limited regarding the link between demographic and socioeconomic factors and child maltreatment among people with disabilities. In Sullivan \& Knutson's (2000) epidemiological study, they found a clear link between the economic status of the child's family and the likelihood of neglect, with children with disabilities from economically disadvantaged communities more likely to suffer neglect. Verdugo and Bermejo (1995) found that as family's socio-economic status decreases, the more severe the maltreatment is.

Studies have differing findings regarding gender, age and racial and ethnic background of children with disabilities experiencing maltreatment. Crosse et al. (1992) and Jonson-Reid et al. (2004) found that males with disabilities were more likely to experience maltreatment, while Sullivan and Knutson (2000) found no gender differences. Regarding age of maltreatment, Sullivan and Knutson (2000) found that children with disabilities were more likely to experience maltreatment at earlier ages than children without disabilities, while Crosse et al. (1992) found that children with disabilities experiencing maltreatment were more likely to be older than four. Similarly, Crosse et al. (1992) found that children with disabilities were more likely to be white, while Jonson-Reid et al. (2004) found that non-white children had an increased likelihood of special education entry.

\subsection{Experiences of children with disabilities in the child welfare system}

While the current research information consistently finds that children with disabilities are more likely to experience maltreatment than children without disabilities, and their experiences of maltreatment may vary based on their disability, there is still little known about experiences of children with disabilities within the child welfare system. While Crosse et al.'s (1992) study provides important information on how many children with disabilities experiencing maltreatment are identified by the child welfare system and Rosenberg and Robinson's (2004) study using AFSCAR data points to the possibility that young children with developmental or medical conditions are more likely to be in out of home placement (Rosenberg \& Robinson, 2004), there is little information about the prevalence of children with disabilities within the system, nor on how likely children with disabilities are to be in out-of-home placement.

There are several reasons why information regarding child welfare and disabilities is limited. There is no standardized collecting of disability data by state child welfare systems, and the Child Abuse Prevention and Treatment Act of 1988 (CAPTA) did not require states to collect such information until only recently. As of 2006 , only $33 \%$ of states' child welfare systems reported documenting information about specific disabilities of children within their system (Shannon \& Agorastou, 2006). The limitations in data collection have been exacerbated by the lack of training of child welfare workers in disability, specifically in identifying children with disabilities (Shannon \& Agorastou, 2006; AAP, 2001; Bonner, Crow, \& Hensley, 1997; Bruhn, 2003; Lightfoot \& LaLiberte, 2006), as well as the lack of standardized definitions of disability or eligibility criteria used across programs and states (Bruhn, 2003; Crosse et al., 1992). Because there has not been a history of standardized reporting, states vary widely on the accuracy of their data. For example, Bruhn (2003) found that in the 1999 AFCARS data set one state reported that none of the children in foster care in the state had a disability, and another reported that only 21 of the more than 30,000 children in foster care in that state had a disability (Bruhn, 2003). Other states reported rates of disability as high as $46.7 \%$. Thus, researchers have not been able to rely on such data for determining national prevalence rates or for comparing prevalence among states, though this might improve in upcoming years with increased reporting requirements.

While there are acknowledged limitations of using state administrative data for research purposes (Drake \& Jonson-Reid, 1999), and for disability data in particular because of some validity questions regarding disability measures based on the medical model, the administrative data that is available for states that do collect data on children with disabilities is somewhat reliable and consistent. This study builds on the strengths of state administrative data (Drake \& Jonson-Reid, 1999) in order to examine the prevalence of children with disabilities with substantiated maltreatment as reported by case workers and administrators in one state's child welfare system. The purpose of this study is:

1) To explore the prevalence and characteristics of children with disabilities with substantiated maltreatment in the child welfare system.

2) To explore the relationships among demographic characteristics (age, race, and location) and the likelihood that a child with substantiated maltreatment in the child welfare system is identified as having a disability.

3) To examine the likelihood that a child with a disability in the child welfare system has been placed in a formal, out-of-home placement.

\section{Methods}

\subsection{Sample}

Minnesota began using a statewide electronic system for collecting child welfare data in 2000 called the Social Service Information System (SSIS). This database contains all the descriptive information on child welfare cases in the 87 Minnesota counties, with records for child protection created based on reports of child maltreatment and investigations. The University of Minnesota has access to these records through the MINN-LInK system, which collects and matches a variety of statewide databases. The SSIS includes demographic information about 
children, including age, race and ethnic background, and disability. In addition, it includes information about type of abuse or neglect and reason for removal. All of the information is entered by case workers. Once children are entered into the system, demographic data stays with a child, though it can be updated as new information emerges. Thus, a child might first enter the system at age 2 with a maltreatment report, and the case worker enters some demographic information into his or her file, such as birth date, or ethnic background. However, if this child re-enters the system at age 8 after a subsequent maltreatment report, and at this time the case worker recognizes that a child has developmental disabilities because of his or her placement in a special education program, she or he can then have a disability code added to his or her SSIS case record. While data through SSIS has been available for analysis since 2001, since the child protection database relies on child welfare workers for entries, it took several years for the data to become reliable. This study uses all SSIS child protection records included between January 1, 2005 and December 31, 2005. In our sample, we only included children who had substantiated cases of maltreatment, meaning that the caseworker determined that maltreatment did occur. The final sample had 6270 children ages $0-18$ who had active child welfare cases through a county child protection agency in Minnesota during 2005.

\subsection{Variables}

Children were classified as having a disability if they had at least one of the 23 disability codes related to children present in the SSIS database. For this analysis, several of the codes were collapsed into a single category. For example, we created a category called developmental disabilities which involved collapsing the four related codes-"developmentally disabled or mental retardation only", "developmentally disabled without mental retardation", "mental retardation with other developmental disability" and "developmentally disabled". Other categories of codes that were created were emotional disturbance (from emotional disturbance not severe and severe); physical disability (from physical disabilityambulation limited to physical disability-ambulation not limited); adult mental illness (from adult mental illness serious and persistent, adult mental illness-acute, to adult mental illness-other) and chemically dependent (from alcohol abuse to drug abuse). Children who had been coded with multiple disability codes were re-coded in one of two ways. If the codes were codes that would have otherwise been collapsed (i.e.: a child had codes for developmental disability, both with mental retardation and with mental retardation as well as other developmental disabilities), than they were recoded into the "new" code of developmental disabilities. Children with multiple, different disability codes (i.e.: visual impairment and emotional disturbance), were recoded into a new category of multiple disabilities. Of the total sample of children in our dataset, 22\% (1383 of 6270) of the total number of children with substantiated maltreatment had a reported disability diagnosis code. As many types of disabilities are not recognized at birth or during early childhood, and children with a disability often do not receive a disability label or diagnosis until they reach elementary school, we also created a category of children with a disability code over age five. Among children in our sample who were over the age of five, $28 \%$ (1112 out of 3982 ) had a reported disability diagnosis code. For both of these, the presence of a disability code was coded as 1 , while the absence of a disability code was coded as 0 .

In our study, we explored the correlation between the presence of a disability with a variety of other characteristics, including race/ ethnicity, gender, rural/urban location, and reason for removal. Race and ethnicity was measured by categories used in SSIS, including Caucasian, African American, Indian/Alaskan Native, Asian, Pacific Islander, and Unable to Determine. We merged the data to create two groups, Caucasian as the reference group (coded as 0), and nonCaucasian. Children were determined to live in a metro county if they resided in the 7 county metro area of Minneapolis/St. Paul (reference group), and they were determined to live in a non-metro county if they resided in any of the remaining Minnesota counties.

Finally, we explored the relationship between disability and out of home placement rates. Out of home placement was determined by whether a child with a disability had been placed out of the home in a formal placement anytime during 2005, excluding informal, kinship care relationships. Thus, out of home placement is a binary variable, with not having an out of home placement during 2005 as the reference group.

\subsection{Data analysis}

We first calculated descriptive statistics regarding the prevalence of children with disabilities with substantiated cases of maltreatment within the child welfare system, and the characteristics of these children, including demographic data, types of disability, geographic location, out of home placement and reason for placement. Then, to estimate the relationship between disability and other characteristics, we conducted a series of binary logistic regression analyses looking at the likelihood a child would have a disability diagnosis based on gender, race, or geographic location. Logistic regression is appropriate in this case because the dependent variable is categorical. Next, to estimate the associations between disability and out of home placement, we used multiple logistic regression with covariance adjustments of gender, age, and rural/urban county.

\subsection{Limitations}

While administrative data such as the SSIS system used in Minnesota can provide useful and reliable information, there are limitations to this study that must be acknowledged resulting primarily from the fact that this data was not collected originally for research purposes. For this study, the codes present in the administrative data were developed for child welfare reports not for disability reports, and thus do not include standard disability classifications, such as the standard or the definition of disability used in federal education policy. For example, in the database children under the age of 18 are sometimes given a disability code of "adult mental illness". The administrative dataset also does not indicate the severity of disability, which would have expanded our understanding of this issue, nor does it include primary disability diagnosis, which limits our ability to determine a primary diagnosis in instances when a child has multiple disability codes. Further, the workers entering in the disability codes likely had varied training in ascertaining disability status, as they were not working in the disability service system. Likewise, as researchers using this data, we are not privy to the decisions that individual workers made when choosing a disability label for a child, so we do not know from this data whether a child already had a disability identified years before, or if the disability is a newly diagnosed condition that came about as a result of the child's involvement in the child welfare system. Thus, the findings of this data must be interpreted with the knowledge that this administrative data was not constructed for the purposes of answering the specific questions in this study. However, despite these limitations, this study draws on a unique population-based data source that helps establish baseline information about children with disabilities in the child welfare system.

\section{Results}

As mentioned above, analysis of the cleaned SSIS data found that $22 \%$ of the 6270 children ages $0-18$ with substantiated maltreatment had a reported disability diagnosis code. Among the 3982 children over the age of 5 with substantiated maltreatment, $27.9 \%$ had a reported disability diagnosis code. Table 1 compares the basic demographic 
variables of children with disability codes in SSIS to children without a disability diagnosis. A higher percentage of children with disabilities were male (55.8\%), Caucasian (63.8\%), and over the age of $5(80.4 \%)$ than children without disabilities. Maltreatment was reported in metroarea counties in $45.8 \%$ of cases involving children with disabilities, compared to $50.6 \%$ of cases involving children without disabilities. Children with disabilities were placed in out-of-home placement in $64.2 \%$ of cases of substantiated maltreatment, while their peers without disabilities were placed in out-of-home placement in $48.9 \%$ of cases. Of children with disabilities, the most common disability codes were emotional disturbance (37.5\%), intellectual/developmental disabilities (10.7\%) and multiple disabilities (9.5\%). These numbers were slightly different for children over the age of 5 (see Table 2).

Next, we did a logistic regression to see if gender, race and county location had an effect on likelihood for a disability label. We found that females were about $38 \%$ less likely to have a disability diagnosis than males (O.R. $=.616, \mathrm{SE}=.072, \mathrm{p}<.001,95 \% \mathrm{CI}=.990-1.318$ ), non-Caucasians with substantiated maltreatment cases were 1.35 times more likely to not have a disability diagnosis in their records than Caucasians (O.R. $=.1 .35, \mathrm{SE}=.082, \mathrm{p}<.001,95 \% \mathrm{CI}=.930-$ 1.199), and children living outside the metropolitan region were about $24 \%$ less likely to have no disability diagnosis than those living in the seven county metro region (O.R. $=.765, \mathrm{SE}=.079, \mathrm{p} .<.001,95 \%$ $\mathrm{CI}=.930-1.230$ ). While the $\mathrm{p}$ values were low, in each instance the 95\% confidence interval includes 1 , thus we cannot conclude the differences are significant.

A logistical regression was then performed to examine the relationship between disability and out of home placement, with the dependent variable being out of home placement, and the independent variables being disability diagnosis, gender, race, and metro/non-metro county. Children of all ages with a disability diagnosis were about 1.87 times more likely to be placed out of home than children without disabilities $(\mathrm{p} .<.001, \mathrm{SE}=.063)$. As school-age children are more likely to have a disability diagnosis due to the prevalence of school-based testing and services, a separate logistic regression was run just with children over age 5 , and among these school-age children, children with disabilities were about 2.16 times more likely to be placed out of home than children without disabilities ( $\mathrm{p} .<.001, \mathrm{SE}=.074)$. While the odds were also higher that children who were male, not Caucasian and non-metro area are more likely to be in out of home placement, the confidence intervals for all three of these variables included 1 and thus are not significant. Table 3 presents the out of home placement data for children over age five.

Table 1

Demographics of children with and without disabilities with substantiated maltreatment.

\begin{tabular}{|c|c|c|c|c|c|c|}
\hline & \multicolumn{2}{|c|}{$\begin{array}{l}\text { Children with } \\
\text { disabilities }\end{array}$} & \multicolumn{2}{|c|}{$\begin{array}{l}\text { Children } \\
\text { without } \\
\text { disabilities }\end{array}$} & \multicolumn{2}{|c|}{$\begin{array}{l}\text { All children with } \\
\text { substantiated } \\
\text { maltreatment }\end{array}$} \\
\hline & $\mathrm{N}$ & Percent & $\mathrm{N}$ & Percent & $\mathrm{N}$ & Percent \\
\hline \multicolumn{7}{|l|}{ Gender } \\
\hline Female & 611 & $44.2 \%$ & 2583 & $52.9 \%$ & 3194 & $50.9 \%$ \\
\hline Male & 772 & $55.8 \%$ & 2304 & $47.1 \%$ & 3076 & $49.1 \%$ \\
\hline \multicolumn{7}{|l|}{ Race } \\
\hline White & 882 & $63.8 \%$ & 2784 & $57.0 \%$ & 3666 & $58.5 \%$ \\
\hline African American & 313 & $22.6 \%$ & 1257 & $25.7 \%$ & 1570 & $25.0 \%$ \\
\hline Native American & 124 & $9.0 \%$ & 479 & $9.8 \%$ & 603 & $9.6 \%$ \\
\hline Asian & 16 & $1.1 \%$ & 132 & $2.7 \%$ & 148 & $2.4 \%$ \\
\hline Unable to determine & 48 & $3.5 \%$ & 235 & $4.8 \%$ & 283 & $4.5 \%$ \\
\hline \multicolumn{7}{|l|}{ Metro/outstate } \\
\hline Urban & 633 & $45.8 \%$ & 2471 & $50.6 \%$ & 3104 & $49.5 \%$ \\
\hline Rural & 750 & $54.2 \%$ & 2416 & $49.4 \%$ & 3166 & $50.5 \%$ \\
\hline Overall & 1383 & $22.1 \%$ & 4887 & $77.9 \%$ & 6270 & $100 \%$ \\
\hline Overall-over 5 & 1112 & $28.6 \%$ & 2870 & $72.1 \%$ & 3982 & $100 \%$ \\
\hline
\end{tabular}

Table 2

Types of disability diagnosis.

\begin{tabular}{lll}
\hline $\begin{array}{l}\text { Type of disability } \\
\text { diagnosis }\end{array}$ & $\begin{array}{l}\text { All children with } \\
\text { disabilities } \\
(\mathrm{n}=1383)\end{array}$ & $\begin{array}{l}\text { Children with } \\
\text { disabilities over 5 } \\
(\mathrm{n}=1112)\end{array}$ \\
\hline Emotional disturbance & $518(37.5 \%)$ & $473(42.5 \%)$ \\
Multiple disability codes & $131(9.5 \%)$ & $127(11.4 \%)$ \\
Developmental disabilities & $148(10.7 \%)$ & $101(9.1 \%)$ \\
Other & $136(9.8 \%)$ & $101(9.1 \%)$ \\
Unknown & $134(9.7 \%)$ & $76(6.8 \%)$ \\
Substance use/abuse & $71(5.1 \%)$ & $67(6.0 \%)$ \\
Currently being evaluated & $97(7.0 \%)$ & $60(5.4 \%)$ \\
Specific learning disabilities & $62(4.5 \%)$ & $51(4.6 \%)$ \\
Speech impairment & $37(2.7 \%)$ & $21(1.9 \%)$ \\
Physical disability & $29(2.1 \%)$ & $20(1.8 \%)$ \\
Hearing impairment & $10(0.2 \%)$ & $7(0.6 \%)$ \\
Adult mental illness & $8(0.6 \%)$ & $6(0.5 \%)$ \\
Visual impairment & $2(0.1 \%)$ & $2(0.2 \%)$ \\
\hline
\end{tabular}

\section{Discussion}

\subsection{Summary of results}

This study finds that more than a fifth $(22 \%)$ of children with a recorded finding of substantiated maltreatment in Minnesota are labeled in administrative records as having a disability, and more than a quarter of children (27.9\%) over age five. This finding echoes earlier findings that children with disabilities were considerably more likely to be maltreated than children without disabilities (Sullivan \& Knutson, 1998), and that children with disabilities are much more likely to be identified by the child welfare system as having been maltreated (Crosse et al., 1992). While children with substantiated maltreatment in Minnesota who are white, male and living in rural areas are more likely to be identified as a disability, these findings were not statistically significant, and thus, we cannot be sure if these differences were due to chance. Further, as this study focused only on county data and did not include children served by tribes, there is a potential undercount of Native American children with disabilities served within the state.

By far the most common disability indicated among the children with substantiated maltreatment was emotional disturbance, with other common disabilities including intellectual and developmental disabilities, substance use and learning disabilities. These high rates of emotional disturbance are not surprising, based on earlier research which indicated high rates of emotional disturbance among children with substantiated maltreatment (Crosse et al., 1992; Jonson-Reid et al., 2004). Another one-fifth (21.6\%) of the children that were labeled with a disability in the administrative records did not have a specific disability indicated in the records, with $9.1 \%$ of the children listed as having an "other" disability, $6.8 \%$ with an "unknown" disability and $5.4 \%$ listed as "currently being evaluated". Because so many children labeled as having a disability did not have a specific disability mentioned, it is not clear if other types of disabilities might also be more prevalent, or why the identification of disabilities was sporadic.

Table 3

Odds ratios from logistic regression of out of home placement for school age children (over age 5).

\begin{tabular}{lll}
\hline Variable & Odds ratio & $95 \%$ confidence interval \\
\hline $\begin{array}{l}\text { Disability } \\
\quad \text { Children with disability }\end{array}$ & $2.16^{\mathrm{a}}$ & $(1.869-2.496)$ \\
Ethnicity & & \\
$\quad$ Not Caucasian & $1.142^{\mathrm{b}}$ & $(.990-1.318)$ \\
Gender & & \\
$\quad$ Male & $1.056^{\mathrm{b}}$ & $(.930-1.199)$ \\
$\quad$ Geographic region & & \\
$\quad$ Non metro area region & 1.069 & $(.930-1.230)$ \\
\hline
\end{tabular}

a Significant at $\mathrm{p}<.001$.

b Significant at $\mathrm{p}<.1$ level. 
This study also finds that children with disabilities of all ages were 1.87 times more likely to be in out of home placement than children without disabilities, and children with disabilities over age five were 2.16 times more likely to be placed out of home than children without disabilities. Thus, not only do children with disabilities make up a high percentage of children identified by the child welfare system as having maltreatment, but once in the system, children with disabilities are also much more likely to be placed out of their home. As other studies have highlighted the difficulties foster parents face when caring for children with disabilities, such as difficulty in obtaining services for foster children with disabilities, lack of appropriate behavior supports and great financial strain (Brown \& Rodger, 2009), our findings suggest that there is a need for greater attention to the presence of children with disabilities within the child welfare system, and particularly in out of home placement.

\subsection{Practice implications}

While this study focused on Minnesota, and there is likely some degree of cross-state difference in cross-system collaboration between disability and child welfare services and funding for disability and child welfare services, the findings do have a number of implications for practice within the child welfare system. First, if children with disabilities are so prevalent in the child welfare system, then it is vital that those working in the child welfare system, such as child welfare workers, foster care providers, and judicial personnel, be aware of issues surrounding children with disabilities. Preparation for child welfare workers and foster care providers should include mandatory training on disability-related issues, and training surrounding disability issues should be seen as a vital preparation for child welfare practice. Second, there is a need for specific, targeted efforts to recruit foster care providers with disability expertise. Certainly, there are therapeutic foster care options for children with emotional disturbances, but similar types of foster care are needed for children with other types of disabilities. Third, as Title II of the Americans with Disabilities Act of 1990 requires that all state and local services be equivalent to people with disabilities, there should be a new emphasis on accessibility of child welfare supports. The ADA requires that children with disabilities involved in the child welfare system, or their parents, have an equal opportunity to benefit from the child welfare system's aids, benefits or services, and thus child welfare agencies must ensure that their services and supports are accessible and modify them appropriately.

In addition, as about a quarter of children involved in the child welfare system have a disability, parenting training classes and other parental supports ought to have a focus on parenting issues involving children with disabilities. Parenting classes with a focus on children with disabilities will ensure that parents of these children are able to access appropriate supports and services. Child welfare organizations could collaborate with disability organizations which already offer parenting classes to parents of children with disabilities to ensure that their parenting classes fit the needs of children with disabilities. Indeed, collaboration between child welfare provider and disability organizations, including state or county developmental disability services or children's mental health, disability parenting organizations, and other disability organizations, such as Centers for Independent Living, are necessary for providing appropriate services. Finally, while there are competencies established in the Ohio Child Welfare Program's Universe of Competencies (Institute for Human Services, 2008) for working with children with developmental disabilities and emotional/behavioral disturbances, there is a need for the focus on best practices in the field in working with children with disabilities in general in the child welfare system in order to better serve this population.

\subsection{Future research}

Along with practice implications, the findings from this study give rise to many other questions. For example, from this study we find that children with disabilities in Minnesota are much more likely to be in out-of-home placement, yet we do not know the reasons for the out of home placement. It is possible that children with disabilities are more likely to be in foster care because the abuse they face is more severe, leading to out of home placement. However, it may also be possible that children who are experiencing maltreatment are labeled as having a disability so they are able to receive services out of the home for which they might not otherwise qualify. It is also possible that parents who have children with disabilities do not have the appropriate supports to care for their children, and thus are at greater risk because of the frustrations that happen related to the lack of supports. Likewise, it is also possible that the disability diagnosis in and of itself makes the system more likely to perceive the risks as being higher, while the risks might not actually be different than for children without disabilities. There is clearly more research needed into the mechanisms that lead children with disabilities to experience maltreatment, and also into the mechanisms that lead children with disabilities with determined maltreatment to be more likely to be placed out of their homes.

There is also a need for further investigation into how children with different types of disabilities fare in the child welfare system. While this study, along with previous studies by Crosse et al. (1992), Sullivan and Knutson (2000) and Jonson-Reid et al. (2004), show that children with certain types of disabilities are more likely to be identified as being maltreated, we do not know how children with different types of disabilities fare in the child welfare system, or if a certain type of disability will impact a child's likelihood to be placed in out of home placement. This is an important area for further investigation.

\section{References}

American Academy of Pediatrics: Committee on Child Abuse and Neglect and Committee on Children with Disabilities (2001). Assessment of maltreatment of children with disabilities. Pediatrics, 108(2), 508-512.

Bonner, B., Crow, S., \& Hensley, L. (1997). State efforts to identify maltreated children with disabilities: A follow-up study. Child Maltreatment, 2(1), 52-60.

Brown, J., \& Rodger, S. (2009). Children with disabilities: Problems faced by foster parents. Children and Youth Services Review, 31, 40-46.

Bruhn, C. (2003). Children with disabilities: Abuse, neglect, and the child welfare system. Journal of Aggression, Maltreatment, and Trauma, 8(1/2), 173-203.

Crosse, S., Kaye, E., \& Ratnofsky, A. (1992). A report on the maltreatment of children with disabilities. Washington DC: Westat, Inc.

Drake, B., \& Jonson-Reid, M. (1999). Some thoughts on increasing the use of administrative data in child maltreatment research. Child Maltreatment, 4, 308-315.

Goerge, R., VanVoorhis, J., Grant, S., Casey, K., \& Robinson, M. (1992). Special-education experiences of foster children: An empirical study. Child Welfare, 71, 419-437.

Horner-Johnson, W., \& Drum, C. (2006). Prevalence of maltreatment of people with intellectual disabilities: A review of recently published research. Mental Retardation and Developmental Disabilities Research Reviews, 12, 57-69.

Institute for Human Services (2008). Ohio Child Welfare Training Program's universe of competencies. Columbus, OH: Institute for Human Services http://www.ocwtp. net/Universe\%20of\%20Competencies.htm Accessed November 30, 2011 from.

Jonson-Reid, M., Drake, B., Kim, J., Porterfield, S., \& Han, L. (2004). A prospective analysis of the relationship between reported child maltreatment and special education eligibility among poor children. Child Maltreatment, 9(4), 382-394.

Lightfoot, E., \& LaLiberte, T. (2006). Approaches to child protection case management for cases involving people with disabilities. Child Abuse E Neglect, 30(4), 381-391.

Rosenberg, S. A., \& Robinson, C. C. (2004). Out-of-home placement for young children with developmental and medical conditions. Children and Youth Services Review, 26(8), 711-723.

Scherr, T. (2007). Educational experiences of children in foster care: Meta-analyses of special education, retention and discipline rates. School Psychology International, 28(4), 419-436.

Shannon, P., \& Agorastou, M. (2006). Identifying children with developmental disabilities receiving child protection services: A national survey of child welfare administrators. Families in Society, 87(3), 351-357.

Smithgall, C., Gladden, R., Yang, D., \& Goerge, R. (2005). Behavior problems and educational disruptions among children in out-of-home care in Chicago. Chapin Hall Working Paper. Chicago, IL: Chapin Hall Center for Children. 
Sobsey, D. (1994). Violence and abuse in the lives of people with disabilities: The end of silent acceptance? Baltimore, MD: Paul H. Brookes.

Sullivan, P. M., \& Knutson, J. F. (1998). The association between child maltreatment and disabilities in a hospital-based epidemiological study. Child Abuse \&'Neglect, 22, 271-288.

Sullivan, P. \& Knutson, J. (2000). Maltreatment and disabilities: a population-based epidemiological study. Child Abuse E Neglect, 24(100), 1257-1273.
Verdugo, M., \& Bermejo, B. (1995). The maltreatment of intellectually handicapped children and adolescents. Child Abuse E Neglect, 19(2), 205-215.

Westcott, H., \& Jones, D. (1999). Annotation: The abuse of disabled children. Journal of Child Psychology and Psychiatry, 40(4), 497-506. 